\title{
Metastatic Extra-Adrenal Pheochromocytoma with Single Kidney and Renal Compromise: A Case Report of Excellent Response, Tolerability, and Outcome to a Modified Regimen of ${ }^{131} \mathrm{I}$-mIBG, and Decision-Making between ${ }^{131}$ I-mIBG Therapy and PRRT
}

\author{
Sarvesh Loharkar ${ }^{1,2}$ Sandip Basu ${ }^{1,2}$ \\ ${ }^{1}$ Radiation Medicine Centre, Bhabha Atomic Research Centre, Tata \\ Memorial Hospital Annexe, Mumbai, Maharashtra, India \\ 2 Homi Bhabha National Institute, Mumbai, Maharashtra, India
}

Address for correspondence Sandip Basu, Radiation Medicine Centre, Tata Memorial Hospital Annexe, Jerbai Wadia Road, Parel, Mumbai 400 012, Maharashtra, India (e-mail: drsanb@yahoo.com).

Ind J Med Paediatr Oncol 2022;43:208-215.

\begin{abstract}
Keywords

- ${ }^{131}$ I-mIBG therapy

- metastatic pheochromocytoma

- paragangliomas

- quality of life

- single kidney

- treatment response
\end{abstract}

Determining the choice and the goal is key element for decision-making of a systemic radionuclide therapy. They should be clearly defined in deciding and individualizing the dose and regimen. For iodine-131 metaiodobenzylguanidine ( ${ }^{131} \mathrm{I}$-mIBG) therapy, the important considerations during dose fractionation include disease burden, tumor biology, functional symptoms, and associated comorbidities, all of which are important determinants for the intent and course of treatment. Herein, we present the case of a 67-year-old elderly female with highly functional metastatic recurrent extra-adrenal pheochromocytoma (presenting 42 years after the primary surgery and 32 years following excision of pararenal recurrence) with multiple comorbidities including single kidney and borderline renal compromise, treated successfully with a relatively lower dose of ${ }^{131} \mathrm{I}$-mIBG (cumulative dose of $22.2 \mathrm{GBq}$ in four cycles with a mean dose of 5.7 GBq per therapy cycle). The excellent tumor burden reduction, hormonal tumor marker response, and most importantly asymptomatic status could be achieved with the administered dose. On follow-up, none of the pretherapeutic parameters (including renal function) showed any further derangement compared with the baseline during next 24 months following the treatment. All cycles were well tolerated with only reversible hematological toxicity that normalized without any active intervention. The report is intended to provide some guidance for future therapeutic regimens. received

July 17,2020

accepted

December 25, 2020

published online

February 2, 2022
DOI https://doi.org/

10.1055/s-0041-1735600. ISSN $0971-5851$.

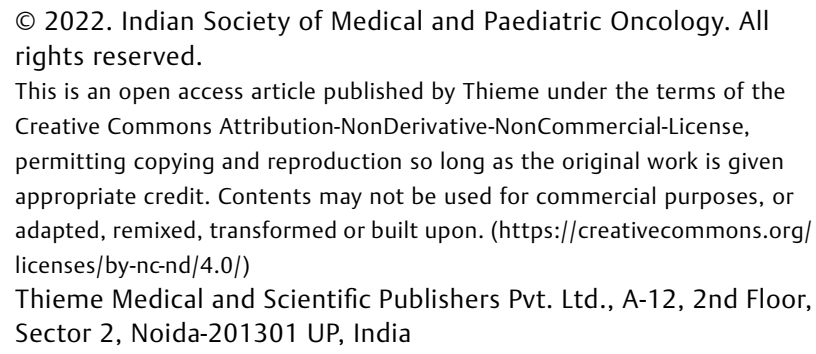

(C) 2022. Indian Society of Medical and Paediatric Oncology. All rights reserved.

This is an open access article published by Thieme under the terms of the Creative Commons Attribution-NonDerivative-NonCommercial-License, permitting copying and reproduction so long as the original work is given appropriate credit. Contents may not be used for commercial purposes, or adapted, remixed, transformed or built upon. (https://creativecommons.org/ licenses/by-nc-nd/4.0/)

Thieme Medical and Scientific Publishers Pvt. Ltd., A-12, 2nd Floor, Sector 2, Noida-201301 UP, India 
Table 1 Data of health-related quality of life assessment (scale: 0 lowest to 5 highest response)

\begin{tabular}{|c|c|c|c|c|c|c|c|c|}
\hline Visits & $\begin{array}{l}0-5 \text { global } \\
\text { health status }\end{array}$ & $\begin{array}{l}\text { Emotional } \\
\text { functioning }\end{array}$ & $\begin{array}{l}\text { Social } \\
\text { functioning }\end{array}$ & $\begin{array}{l}\text { Physical } \\
\text { functioning }\end{array}$ & Diarrhea & Cough & Fatigue & $\begin{array}{l}\text { Fear of } \\
\text { future } \\
\text { health }\end{array}$ \\
\hline Pre-mIBG1 & 2 & 1 & 3 & 2 & 4 & 3 & 4 & 4 \\
\hline Post-3 months mIBG 1 & 3 & 2 & 3 & 2 & 3 & 2 & 3 & 2 \\
\hline Post-3 months mIBG 2 & 3 & 3 & 4 & 3 & 2 & 1 & 3 & 2 \\
\hline Post-3 months mIBG 3 & 3 & 4 & 4 & 3 & 1 & 0 & 3 & 2 \\
\hline Post-3 months mIBG 4 & 4 & 4 & 4 & 3 & 0 & 0 & 3 & 2 \\
\hline Post-6 months mIBG 4 & 4 & 4 & 4 & 3 & 0 & 0 & 3 & 2 \\
\hline
\end{tabular}

Abbreviation: mIBG, metaiodobenzylguanidine.

\section{Introduction}

Neural crest cell-derived tumors are extremely diverse; of them tumors consisting of sympathetic-adrenal cell lineage comprise pheochromocytomas (PCCs), paragangliomas (PGLs), neuroblastomas, and others. The majority of PCCs/PGLs are benign, with 10 to $20 \%$ extra-adrenal PGLs showing malignant course of disease and metastasis. ${ }^{1-3}$ The prognosis in malignant PGL/PCC is poor with overall 5-year survival $<50 \%$. The diagnostic workup includes blood/urinary levels of catecholamines or their metabolites, functional and anatomical imaging including iodine-131 metaiodobenzylguanidine ( $\left.{ }^{131} \mathrm{I}-\mathrm{mIBG}\right)$ and fluorodeoxyglucose positron emission tomography/computed tomography (FDG-PET/CT) and somatostatin receptor (SSTR)-based imaging, and tissue diagnosis with IHC markers. The management in metastatic cases remains mainly palliative and includes multimodality approach comprising ${ }^{131} \mathrm{I}$-mIBG therapy, SSTR-targeted therapies, chemotherapy, surgical debulking (where feasible), and novel antineoplastic agents. ${ }^{2-4}$

As mIBG is an analog of norepinephrine and has high affinity to chromaffin cells and derived tumors, it has been used for molecular imaging and targeted therapy with success for these tumors since $1984 .^{5-7}$ Its uptake and retention take place both by an active, ATP-dependent process known as "uptake-1"(major pathway) and energy-independent passive diffusion ${ }^{7}$ and have proven capability of selectively delivering substantial radiation dose to the tumor cells in both primary tumor and metastatic lesions. ${ }^{131}$ I-mIBG therapy is usually well tolerated even in the pediatric population when compared with chemotherapeutic regimens. The reported immediate adverse effects are nausea, vomiting, transient myelosuppression-prominently isolated thrombocytopenia (more common with chemotherapy), and rarely delayed effects-thyroid hypofunction and persistent myelosuppression. ${ }^{8-10}$

${ }^{131} \mathrm{I}-\mathrm{mIBG}$ is usually administered as a fixed activity/according to patient weight ${ }^{9-11}$ alternative approach is to modify according to whole-body absorbed dose. As in myelosuppression, the dosages are also modified in impaired renal function as ${ }^{131} \mathrm{I}-\mathrm{mIBG}$ is principally excreted in the urine. ${ }^{12}$ Herein, the authors present the gratifying response and excellent tolerability profile following ${ }^{131} \mathrm{I}-\mathrm{mIBG}$ therapy with modified dose regimen including highlighting the typical therapy management involving pretherapy workup and posttreatment follow-up in a patient of metastatic extra-adrenal PCC with single kidney and baseline renal compromise and multiple other comorbidities.

\section{Case Report}

A 67-year-old female, known diabetic and hypertensive, with a history of open laparotomy due to abdominal symptoms 42 years ago concluded as left extra-adrenal tumor underwent mass excision first and again had left pararenal tumor recurrence for which she underwent excision and left nephrectomy 10 years after first surgery; the histopathology report inferred as extra-adrenal PCC. After 30 years, she had no significant symptoms and had been followed up in the initial years with yearly $\mathrm{X}$-rays and clinical examination and abdominal ultrasound.

In her present history, around 18 to 20 months prior to the first cycle of ${ }^{131} \mathrm{I}-\mathrm{mIBG}$ therapy cycle, she presented with cough (for $>3$ months) and diarrhea; on biochemical investigations she showed raised 24-hour urinary vanillylmandelic acid (VMA), which was $9.5 \mathrm{mg} / 24$ hours (normal $<7$ ), plasma-free metanephrine (PFM) was $537.9 \mathrm{pg} / \mathrm{mL}$ (normal $<60 \mathrm{pg} / \mathrm{mL}$ ), and plasma-free normetanephrine (PFN) was $1227.0 \mathrm{pg} / \mathrm{mL}$ (normal $<140 \mathrm{pg} / \mathrm{mL}$ ). Her blood pressure (BP) was $180 / 100 \mathrm{~mm} \mathrm{Hg}$; evaluation with contrast-enhanced CT abdomen and chest showed a $2.2 \times 1.5 \mathrm{~cm}$ enhancing, soft tissue lesion around the left adrenal gland, multiple rounded lung nodules, largest $\sim 1.4 \times 1.4 \mathrm{~cm}$, and abdominal lymph nodes (largest $\sim 1.4 \mathrm{~cm} \times 1.0 \mathrm{~cm}$, pre-aortic). ${ }^{18} \mathrm{~F}$-FDG PET/CT scan showed no significant tracer concentration in any of these lesions.

The patient commenced long-acting somatostatin analog (injection Sandostatin $30 \mathrm{mg}$ LAR intramuscularly) per 3 weeks and other antihypertensive and antidiabetic medications including insulin by a local medical oncologist. Within 3 months the BP was 130/80 mm Hg and biochemical tests also showed reduced values of VMA to $6.1 \mathrm{mg} / 24$ hours, PFM to $52.0 \mathrm{pg} / \mathrm{mL}$, and PFN to $750.0 \mathrm{pg} / \mathrm{mL}$. After this initial period of 15 to 18 months on medication, the patient showed few spikes in BP as the highest noted was $180 / 100 \mathrm{~mm} \mathrm{Hg}$ with VMA raised to $27.9 \mathrm{mg} / 24$ hours. Further 3 months 

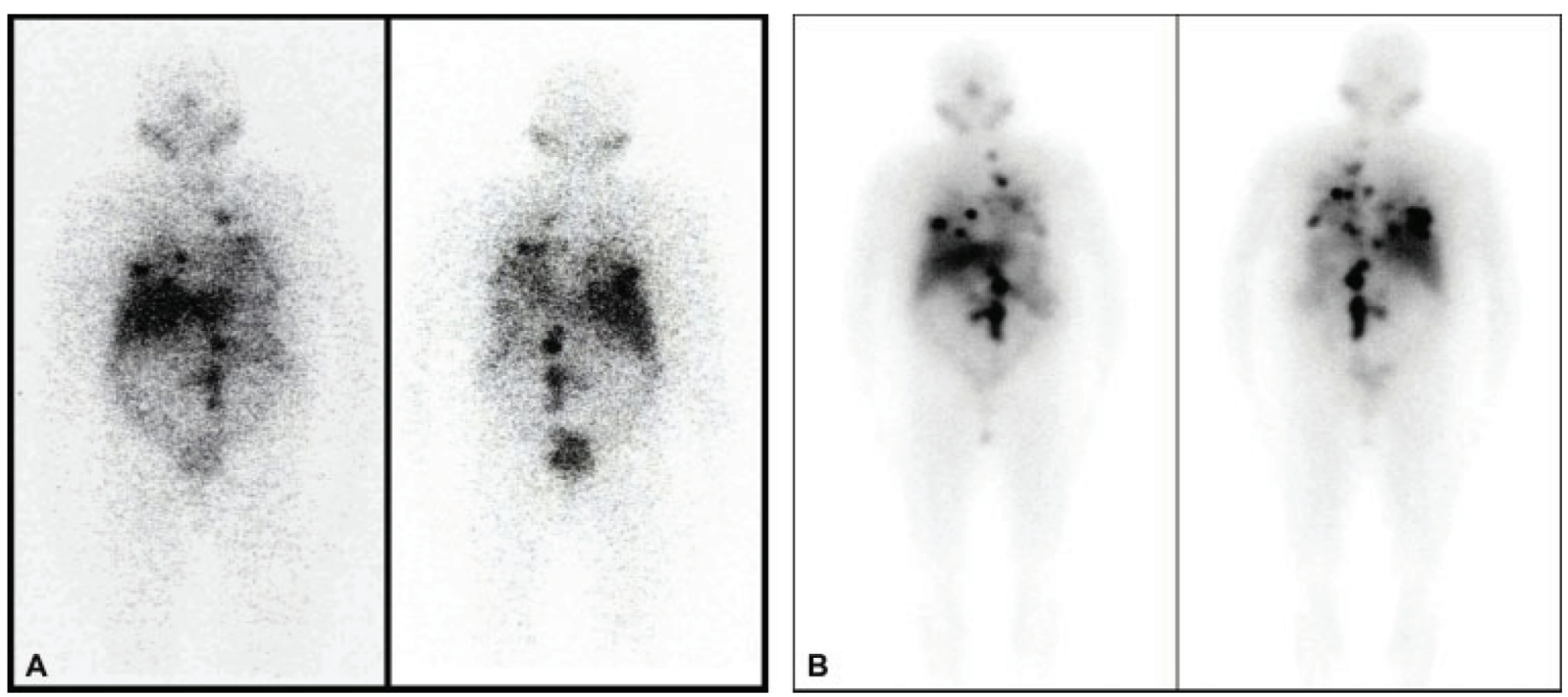

Fig. 1 Baseline diagnostic iodine-131 metaiodobenzylguanidine $\left({ }^{131} \mathrm{I}-\mathrm{mIBG}\right)$ scan (A) showing multiple foci of increased tracer uptake in the bilateral lung fields and midabdomen. Post first ${ }^{131} \mathrm{I}$-mIBG therapy planar scan (B) with multiple foci of increased tracer uptake noted in the bilateral lung fields and midabdomen.

later, there was raised PFM of $130.7 \mathrm{pg} / \mathrm{mL}$ and PFN of 2143 $\mathrm{pg} / \mathrm{mL}$. She did not show relief in her diarrhea and lost $>6 \mathrm{~kg}$ of weight (from 63 to $56 \mathrm{~kg}$ ) in the previous 1 year (prior to mIBG therapy). She also showed deterioration of her renal functions (serum creatinine from 1.02 to $1.5 \mathrm{mg} / \mathrm{dL}$ ) and got referred to nuclear medicine for the consideration of appropriate radionuclide therapy. She underwent $1 \mathrm{mCi}$ diagnostic ${ }^{131}$ I-metaiodobenzylguanidine (mIBG) whole-body scan (-Fig. 1), which showed multiple foci of increased tracer uptake in the bilateral lung fields and midabdomen, which on further single-photon emission CT (SPECT/CT) correlation showed tracer concentrating multiple abdominal nodes and bilateral lung nodules.

In view of age, Eastern Cooperative Oncology Group performance status of 2 , and nephrectomized status (with serum creatinine value $1.5 \mathrm{mg} / \mathrm{dL}$ and estimated glomerular filtration rate [eGFR] of $34.0 \mathrm{~mL} / \mathrm{min}$ ), she was first considered for ${ }^{131} \mathrm{I}-\mathrm{mIBG}$ therapy rather than peptide receptor radionuclide therapy (PRRT). She was treated with $5,254 \mathrm{MBq}$ (142 $\mathrm{mCi}){ }^{131} \mathrm{I}-\mathrm{mIBG}$ by intravenous infusion over 3.5 hours. Posttherapy planar scan (-Fig. 2) showed multiple foci of increased tracer uptake was noted in bilateral lung fields and midabdomen. VMA, PFM, and PFN showed 300 to $400 \%$ reduction from pretherapy values (from 27.9 to $1.6 \mathrm{mg} / 24$ hours for VMA, 130.7 to $22.0 \mathrm{pg} / \mathrm{mL}$ for PFM, and 2,143 to $492.4 \mathrm{pg} / \mathrm{mL}$ for PFN) and controlled hypertension after 3 months of follow-up. She was treated with ${ }^{131}$ I-mIBG two times subsequently at an interval of 12 weeks with a dose of $6512 \mathrm{MBq}(176 \mathrm{mCi})$ and 5,476 MBq (148 mCi). All therapies were well tolerated, with no significant adverse effect in the first 24 hours of treatment. In view of clinically asymptomatic status and excellent response, the fourth cycle of therapy was planned after some spacing around 9 months after third cycle and 5,735Mbq (155 mCi) of dose was given; this time patient showed clinically asymptomatic grade 3 hematological toxicity after 6 weeks of therapy that got reversed but over a period of 8 to 12 weeks. The VMA and
PFM levels were constantly within normal range after first cycle. PFN levels were higher than normal limits, but 400 to $500 \%$ less than pretherapy values (from 2,143 to 371 $\mathrm{pg} / \mathrm{mL}$; - Fig. 2). Adequate thyroid blockade using SSKI solution started from 1 day before therapy that is continued up to 14 days post-therapy and absence of ${ }^{131}$ I-mIBG uptake interfering medications was ensured at every therapy; this was verified with posttherapy scans and the thyroid function values were normal.

The pretherapy ${ }^{131}$ I-mIBG scan (-Fig. 3) before the last therapy showed tracer-avid bilateral lung fields and only small portion of left paravertebral regions. SPECT/CT correlation showed tracers concentrating left subcentimetric para-aortic lymph node and multiple bilateral lung nodules; no new sites were revealed. Comparing with first pretherapy scan, overall suggestive of partial response to therapy, multiple lesions showed reduced size and disappearance of few abdominal nodal lesions. On her follow-up from baseline to recent visit (6 months after the last therapy), significant symptomatic improvement was documented with complete disappearance of her primary complaint of diarrhea and cough (-Table 1). She did not show any paroxysmal hypertensive episodes with maintained BP in the range of 140 to 110 (systolic BP)/90-76 (diastolic BP). She had also gained $8 \mathrm{~kg}$ of weight in this period of 1 year (-Fig. 4). Assessment of quality of life using specially made intuitional questionnaire showed improvement in all subscales (-Fig. 5).

The follow-up hematological profiles, renal function, and LFTs tests were performed fortnightly for 12 weeks following treatment and during the pretherapy workup of subsequent therapies. The serum creatinine remained within control (varying between 1.10 and 1.60) while corresponding eGFR values varied between 45.0 and 30.6), improving following the ${ }^{131} \mathrm{I}-\mathrm{mIBG}$ therapy when compared to their baseline data (-Fig. 6). These revealed asymptomatic grade 1 hematological toxicity (according to the NCI CTCAE [National Cancer Institute: Common Terminology Criteria for Adverse Events] 


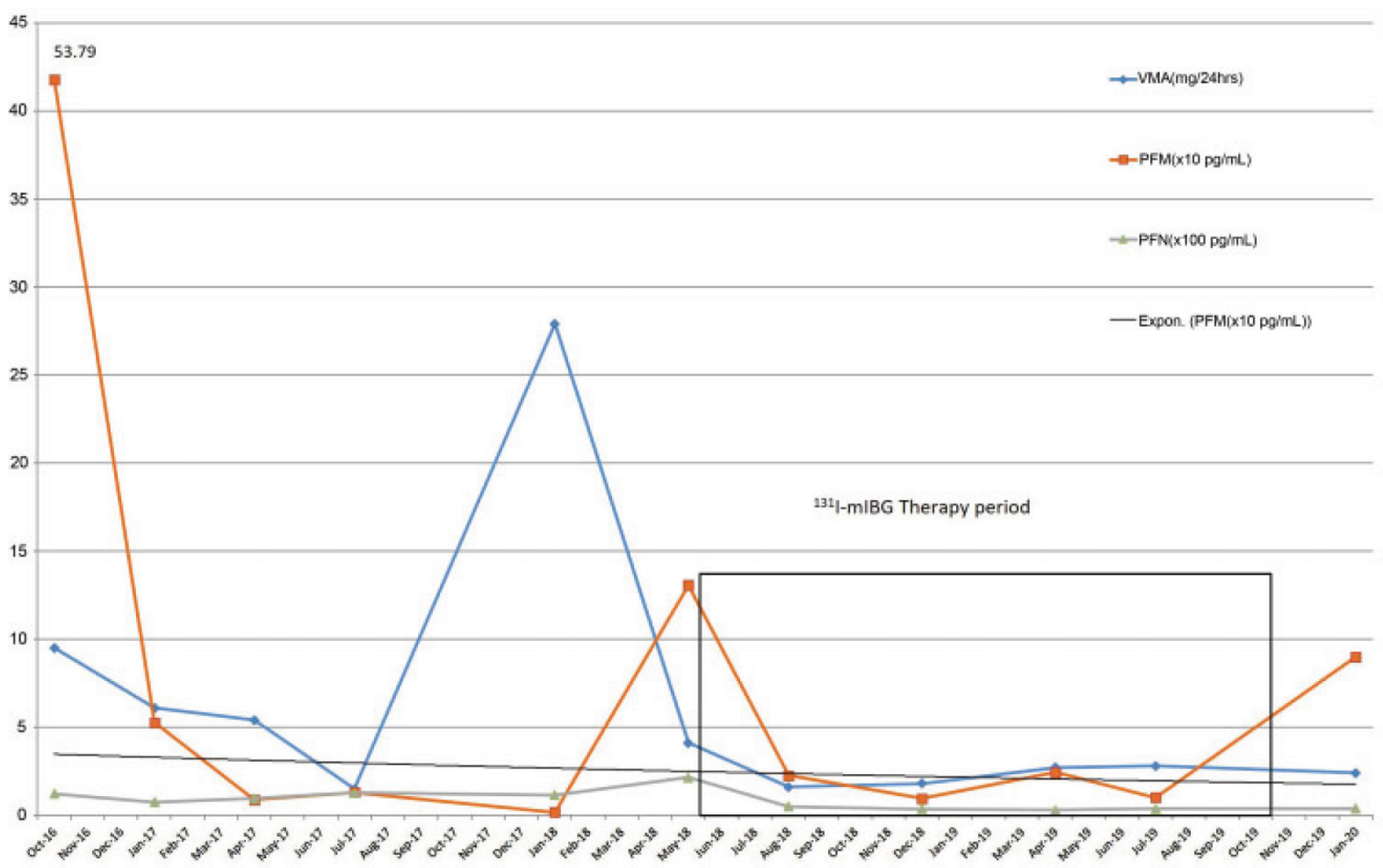

Fig. 2 Line graph showing values of three tumor markers (vanillylmandelic acid, plasma-free metanephrine, and plasma-free normetanephrine before and over the period of multiple therapies).

Grading System) as predominantly thrombocytopenia 4 weeks after therapy, which returned to normal range in 6 to 8 weeks after the therapy ( $\mathbf{- F i g . ~} \mathbf{7}$ ).

\section{Discussion}

The neural crest tumors are relatively uncommon and widely heterogeneous class of tumors. Although malignant variants are less common, they contribute to high mortality and morbidity owing to their functional status and variable response to different therapies. It is observed that among neural crest tumors in adults, the PCCs and the PGLs arising in the abdomen secrete catecholamines and contribute to added morbidity. Being associated with several molecular markers such as VEGF, N-cadherin, and telomerase catalytic subunit, this subclass of metastatic tumors is generally considered poor responder to multiple therapeutic options available. $^{13}$ Such tumors may show recurrence even 8 to 10 years after initial complete response, ${ }^{14}$ which was seen in our case (42 years after first surgery and 32 years after recurrence). It necessitates stringent surveillance for long period even after complete response. Systematic review and meta-analysis have proven role of ${ }^{131} \mathrm{I}-\mathrm{mIBG}$ therapy in these tumors $^{15}$ and combination of ${ }^{131}$ I-mIBG therapy with chemotherapy did not show any superior result, but an increased toxicity and hence not recommended. ${ }^{16}$

There is no definite agreement on policy about dosage of ${ }^{131} \mathrm{I}$-mIBG in this group of patients; the review of literature shows varying dosage from 3.7 to $9.5 \mathrm{GBq} .{ }^{17}$ One of the widely used dosage schedules is median initial dose of $7.4 \mathrm{GBq}$ (200
$\mathrm{mCi}$ ) and median cumulative dose of $22.2 \mathrm{GBq}$ with a range of 6.8 to $81.4 \mathrm{GBq}$ depending on the case. ${ }^{18}$ Few investigators have also tried with escalated dosage of ${ }^{131}$ I-mIBG with a median single treatment dose of $30 \mathrm{GBqs}$ or $11.5 \mathrm{mCi} / \mathrm{kg}$ (range, $5.6-18.3 \mathrm{mCi} / \mathrm{kg}$ ) that showed promising results but with significant toxicities. ${ }^{19}$ Multiple comorbidities including one-sided nephrectomy with renal compromise, hyperuricemia, and elderly age as presented here require personalized approach with rigorous workup throughout the therapies. ${ }^{20}$

The excretion of ${ }^{131} \mathrm{I}-\mathrm{mIBG}$ is not well understood at the molecular level, but recent studies revealed that it is transported by organification transporter 2/toxin extrusion proteins hMATEs (multidrug and toxin extrusion proteins) pathway involved in active secretion. ${ }^{131}$ I-mIBG excretion rate over the first 24 hours is only partially related to the GFR. $^{21}$ This makes ${ }^{131} \mathrm{I}$-mIBG quite safer in renal compromise, especially when compared with other radionuclide therapies such as PRRT $\left({ }^{177} \mathrm{Lu} /{ }^{90}\right.$ Y-DOTATATE $) .{ }^{20}$ Furthermore, ${ }^{131} \mathrm{I}$ mIBG is theoretically superior owing to the physical characteristics of harder $\beta$-emission of ${ }^{131} \mathrm{I}$ compared with ${ }^{177} \mathrm{Lu}\left(\mathrm{E}_{\beta \max }\right.$ 0.6 vs. $0.497 \mathrm{MeV}$ ). The impression of renal safety was reflected in our case where renal parameters remained in pretherapy ranges (-Fig. 6) without any special measure except dose adjustments (with a median dose of $5.55 \mathrm{GBq}$ per cycle). The patient received a cumulative dose of $23 \mathrm{GBq}$ in four cycles with a mean dose of $5.7 \mathrm{GBq}$ per therapy cycle. At 24 months following the first cycle of ${ }^{131} \mathrm{I}$-mIBG therapy, she is asymptomatic with normal daily activities.

The hematological complications are most common side effects and generally recover spontaneously; the same 

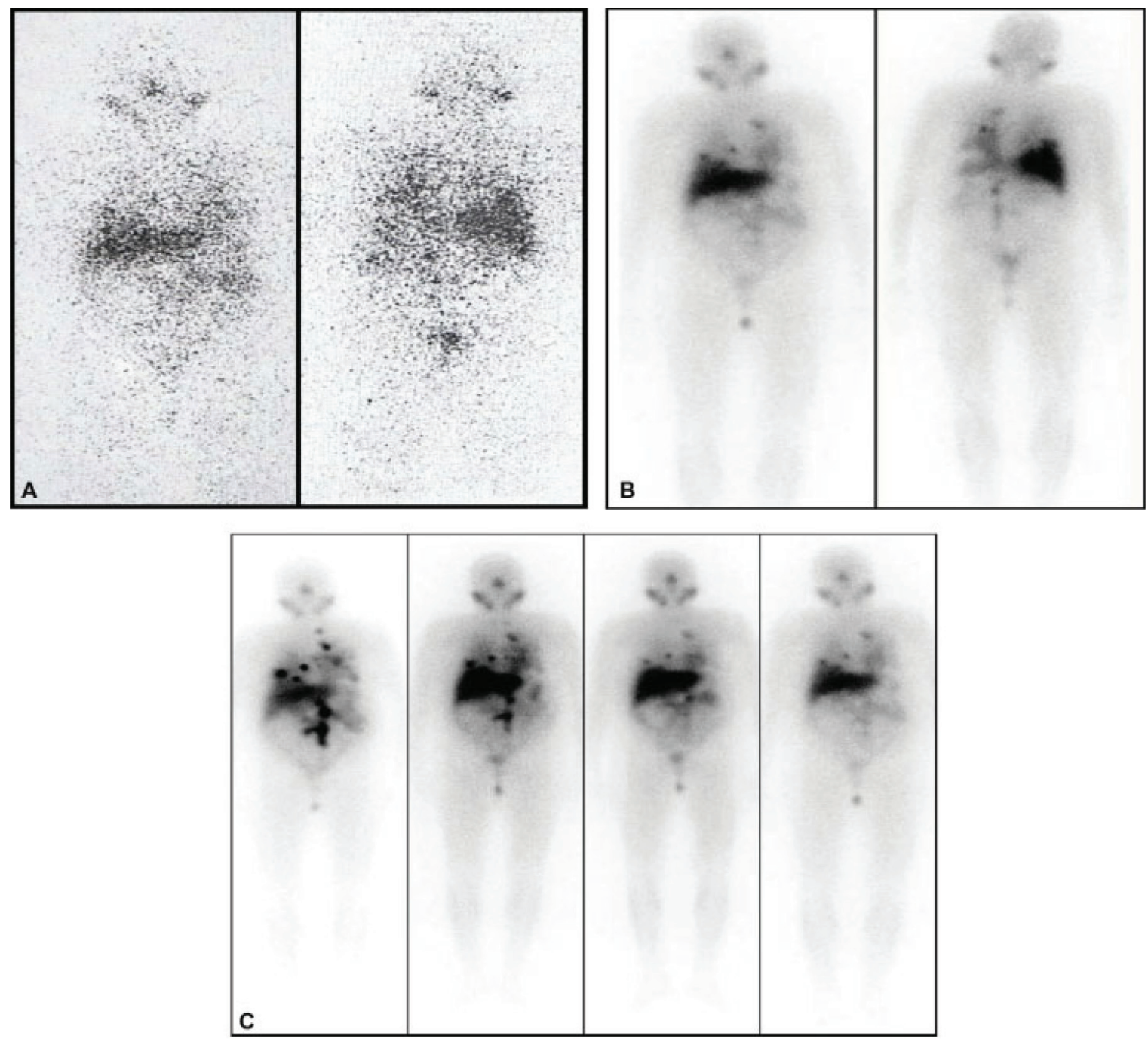

$\cdots$

Fig. 3 The fourth pretherapy iodine-131 metaiodobenzylguanidine $\left({ }^{131} \mathrm{I}-\mathrm{mIBG}\right)$ scan (A) showing small foci of increased tracer uptake in the left paravertebral region noted in the bilateral lung fields. Post fourth cycle of ${ }^{131} \mathrm{I}$-mIBG therapy planar scan (B) with multiple foci of increased tracer uptake noted in the bilateral lung fields and midabdomen (note reduced sites and intensity of uptake compared with first posttherapy scans in - Fig. 1). (C) Post- ${ }^{131} \mathrm{I}$-mIBG therapy anterior planar scans of all four cycles with multiple foci of increased tracer uptake noted in the bilateral lung fields and midabdomen (note reducing sites and intensity of uptake with each cycle).

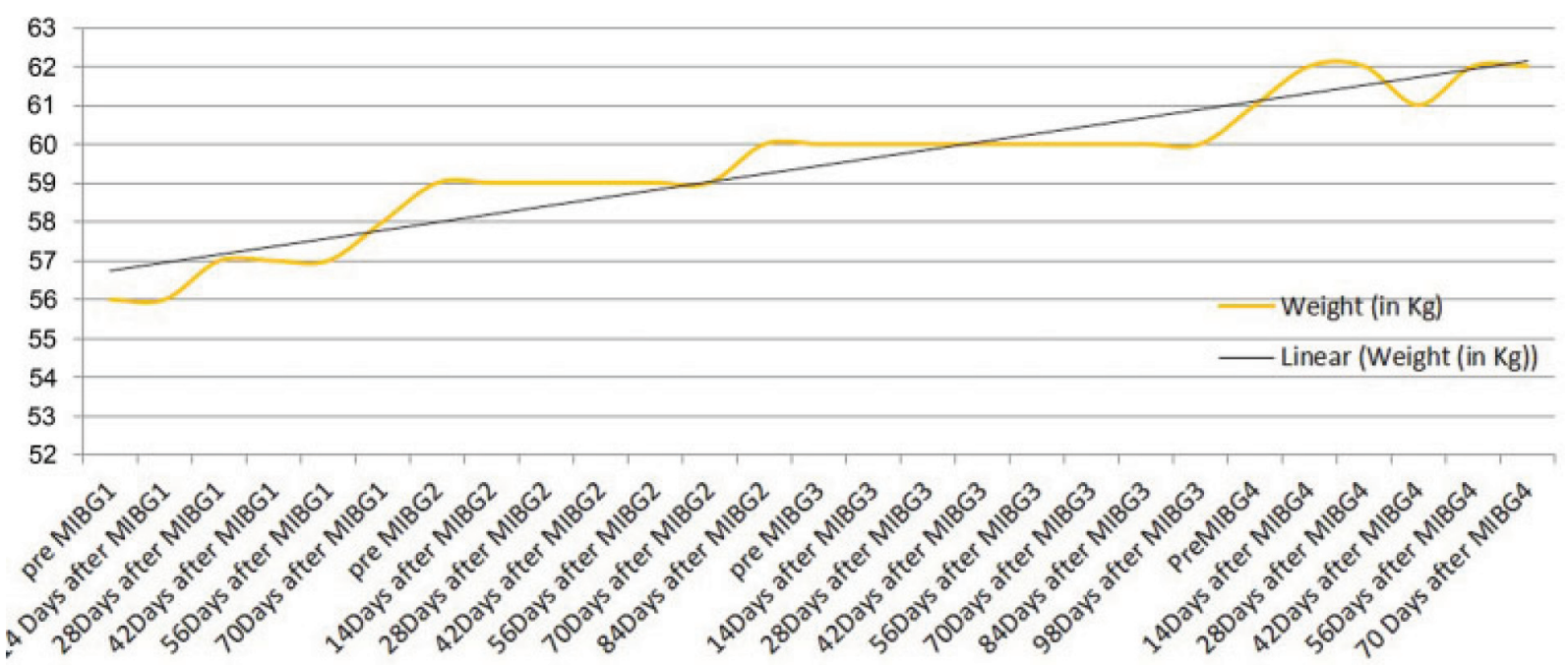

Fig. 4 Line graph showing weight in kg over the period of therapy and during follow-up. 


\section{QoL Assesment}

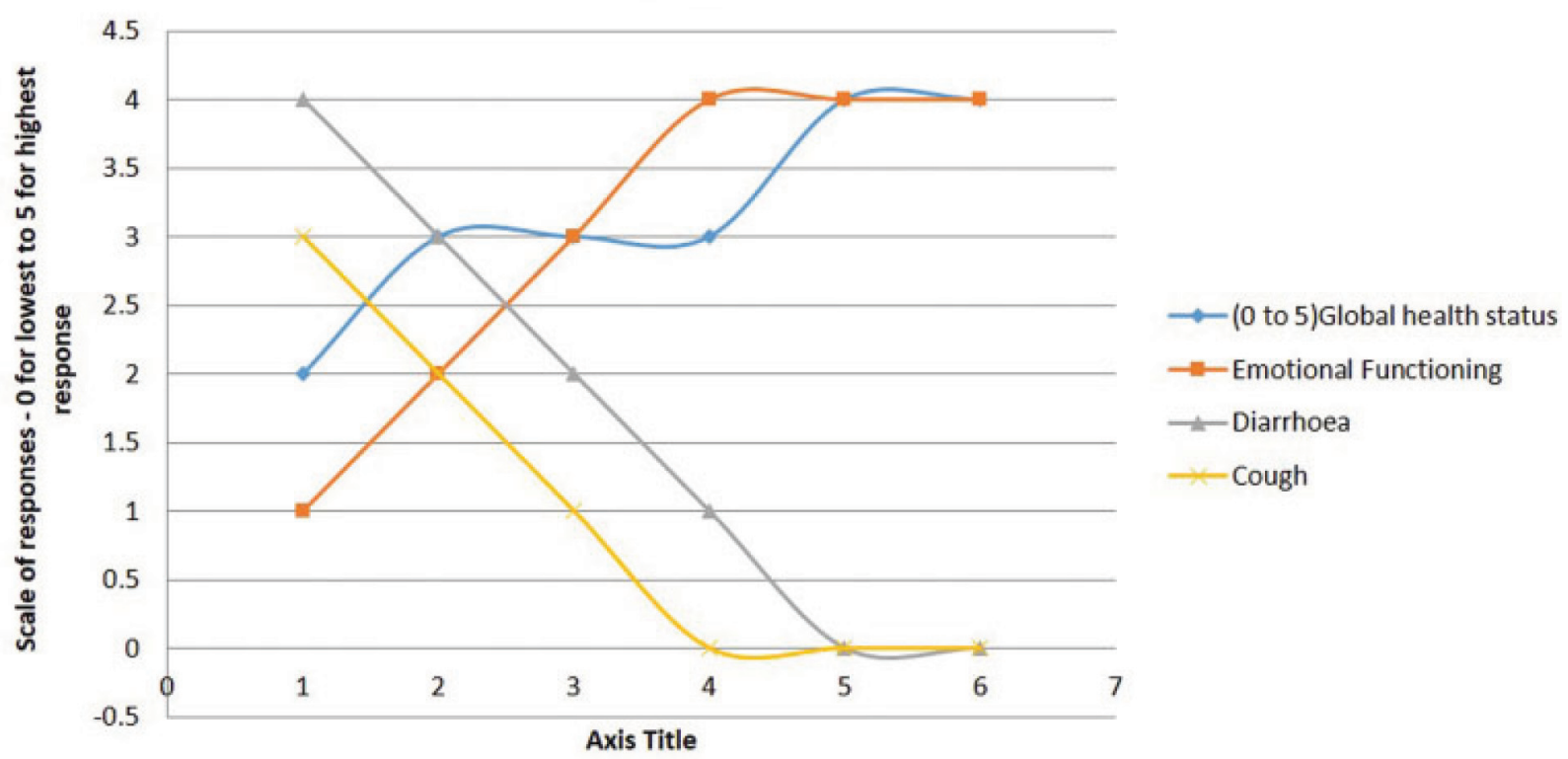

Fig. 5 Line graph of health-related quality of life assessment (scale: 0 lowest to 5 highest response).

\section{eGFR over period of ${ }^{131}$ I-mIBG therapy}

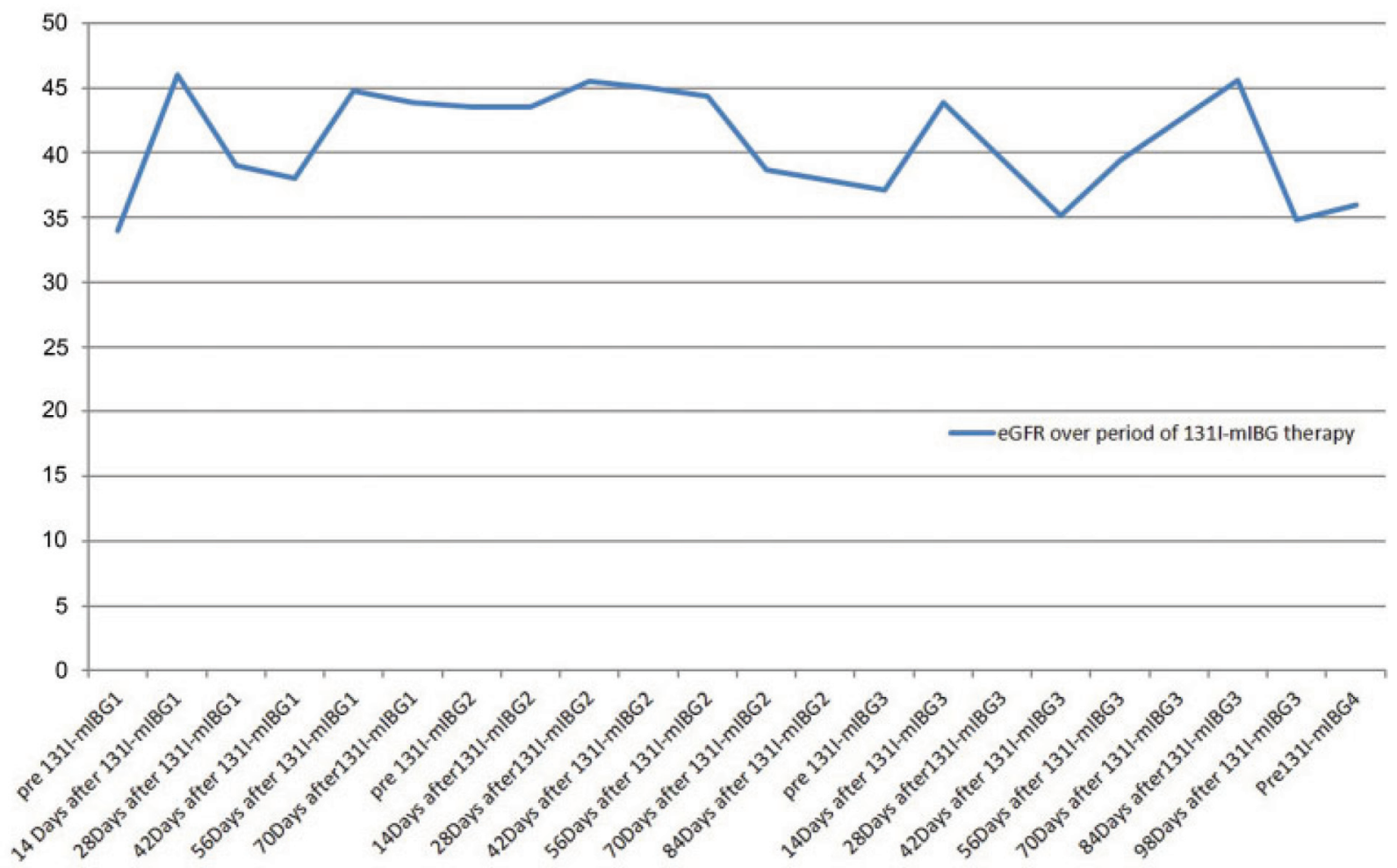

Fig. 6 Line graph showing trend of estimated glomerular filtration rate $(\mathrm{mL} / \mathrm{min})$ over the period of therapy.

findings got reflected in our case, showing typical pattern of deranging hemograms at every cycle, especially platelets (also hemoglobin) and spontaneous correction within a specific time period of 6 to 10 weeks ( - Fig. 7).
The goal of each therapy and cycle should be even clearly defined and plays a pivotal role in individualizing the ${ }^{131} \mathrm{I}-$ mIBG therapy. ${ }^{22}$ The important considerations during dose fractionation in ${ }^{131} \mathrm{I}-\mathrm{mIBG}$ therapy should be tumor biology, 
Platelet count trend over period of 131I-mIBG therapy

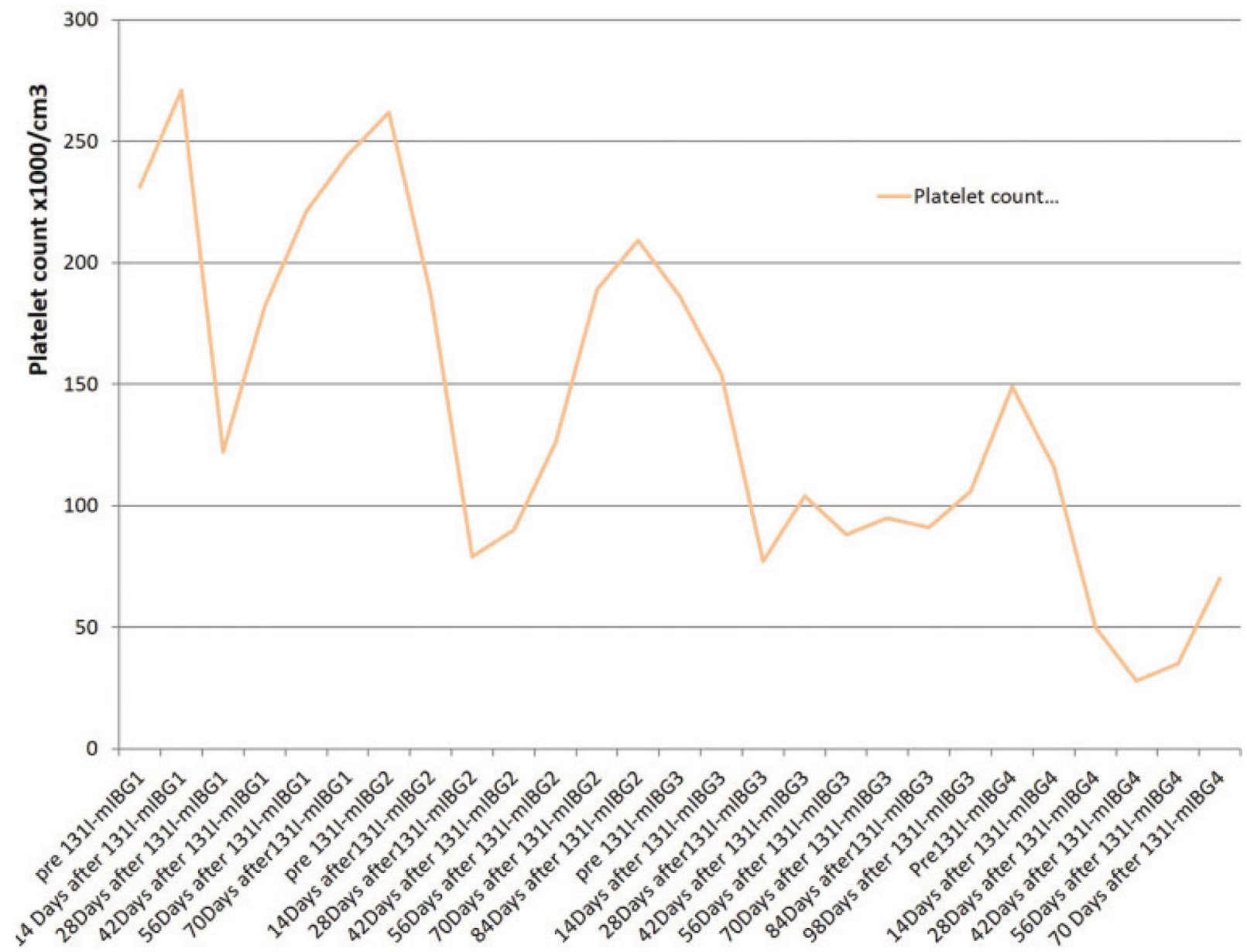

Fig. 7 Line graph showing trend of platelet counts over the period of therapy.

disease burden, and functional symptoms, thereby determining the intent of therapy. In the above-mentioned case with highly functional, progressive symptomatic and metastatic disease in an elderly patient with renal compromise, early symptom control and disease stabilization were achieved with repetitive treatments with smaller doses. Further studies with larger number of cases with dose adjustment and tolerability guidance, especially in deranged renal, hematological, and hepatic functional status, are merited.

\section{Conclusion}

Thus, in this case report, the authors describe the use of ${ }^{131} \mathrm{I}$ mIBG imaging and therapy to treat recurrent metastatic PCC. Taking into account the aims of treatment in a patient of advanced years with complicating factors, the patient was treated with four cycles of ${ }^{131} \mathrm{I}-\mathrm{mIBG}$, resulting in clinical response and diminution of symptoms at up to 6 months after the fourth cycle. Dose was determined based on imaging data and patient-specific comorbidity factors and was at the lower range of the published range $(23 \mathrm{GBq}$ compared with $6.8-81.4 \mathrm{GBq})$. The report is intended to provide some guidance for future therapeutic regimens for systemic radionuclide therapies in patient-specific manner.

\section{Declaration of Patient Consent}

The authors certify that they have obtained all appropriate patient consent forms.

\section{Financial Support and Sponsorship} Nil.

Conflict of Interest

None declared.

\section{References}

1 Chrisoulidou A, Kaltsas G, Ilias I, Grossman AB. The diagnosis and management of malignant phaeochromocytoma and paraganglioma. Endocr Relat Cancer 2007;14(03):569-585

2 Adjallé R, Plouin PF, Pacak K, Lehnert H. Treatment of malignant pheochromocytoma. Horm Metab Res 2009;41(09):687-696

3 Kundu S, Kand P, Basu S. Comparative evaluation of iodine-131 metaiodobenzylguanidine and 18-fluorodeoxyglucose positron emission tomography in assessing neural crest tumors: will they play a complementary role? South Asian J Cancer 2017;6(01):31-34 
4 Tan TH, Hussein Z, Saad FF, Shuaib IL. Diagnostic performance of (68)Ga-DOTATATE PET/CT, (18)F-FDG PET/CT and (131)I-MIBG scintigraphy in mapping metastatic pheochromocytoma and paraganglioma. Nucl Med Mol Imaging 2015;49(02):143-151

5 Sisson JC, Shapiro B, Beierwaltes WH, et al. Radiopharmaceutical treatment of malignant pheochromocytoma. J Nucl Med 1984;25 (02):197-206

6 Hoefnagel CA. Radionuclide therapy revisited. Eur J Nucl Med 1991;18(06):408-431

7 Fitzgerald PA, Goldsby RE, Huberty JP, et al. Malignant pheochromocytomas and paragangliomas: a phase II study of therapy with high-dose 131I-metaiodobenzylguanidine (131I-MIBG). Ann N Y Acad Sci 2006;1073:465-490

8 Wafelman AR, Hoefnagel CA, Maes RA, Beijnen JH. Radioiodinated metaiodobenzylguanidine: a review of its biodistribution and pharmacokinetics, drug interactions, cytotoxicity and dosimetry. Eur J Nucl Med 1994;21(06):545-559

9 Basu S, Nair N. Stable disease and improved health-related quality of life (HRQoL) following fractionated low dose 131I-metaiodobenzylguanidine (MIBG) therapy in metastatic paediatric paraganglioma: observation on false "reverse" discordance during pre-therapy work up and its implication for patient selection for high dose targeted therapy. Br J Radiol 2006;79(944):e53-e58

10 Rachh SH, Abhyankar S, Basu S. $\left[{ }^{131}\right.$ I]Metaiodobenzylguanidine therapy in neural crest tumors: varying outcome in different histopathologies. Nucl Med Commun 2011;32(12): $1201-1210$

11 Matthay KK, Weiss B, Villablanca JG, et al. Dose escalation study of no-carrier-added 131I-metaiodobenzylguanidine for relapsed or refractory neuroblastoma: new approaches to neuroblastoma therapy consortium trial. J Nucl Med 2012;53(07):1155-1163

12 Tobes MC, Fig LM, Carey J, Geatti O, Sisson JC, Shapiro B. Alterations of iodine-131 MIBG biodistribution in an anephric patient: comparison to normal and impaired renal function. J Nucl Med 1989;30(09):1476-1482
13 Boltze C, Mundschenk J, Unger N, et al. Expression profile of the telomeric complex discriminates between benign and malignant pheochromocytoma. J Clin Endocrinol Metab 2003;88(09): 4280-4286

14 Kapur S, Iqbal AN, Levin MB. A case of malignant metastatic pheochromocytoma after eight years of primary diagnosis. World J Oncol 2014;5(01):33-40

15 van Hulsteijn LT, Niemeijer ND, Dekkers OM, Corssmit EP. (131)IMIBG therapy for malignant paraganglioma and phaeochromocytoma: systematic review and meta-analysis. Clin Endocrinol (Oxf) 2014;80(04):487-501

16 Kaltsas GA, Mukherjee JJ, Foley R, Britton KE. Treatment of metastatic pheochromocytoma and paraganglioma with 1311-metaiodobenzylguanidine (MIBG). Endocrinologist 2001;13:321-333

17 Troncone L, Rufini V. 131I-MIBG therapy of neural crest tumours (review). Anticancer Res 1997;17(3B):1823-1831

18 Gedik GK, Hoefnagel CA, Bais E, Olmos RA. 131I-MIBG therapy in metastatic phaeochromocytoma and paraganglioma. Eur J Nucl Med Mol Imaging 2008;35(04):725-733

19 Rose B, Matthay KK, Price D, et al. High-dose 131I-metaiodobenzylguanidine therapy for 12 patients with malignant pheochromocytoma. Cancer 2003;98(02):239-248

20 Basu S, Abhyankar A, Jatale P. The current place and indications of 131I-metaiodobenzylguanidine therapy in the era of peptide receptor radionuclide therapy: determinants to consider for evolving the best practice and envisioning a personalized approach. Nucl Med Commun 2015;36(01):1-7

21 Wafelman AR, Nortier YL, Rosing H, et al. Renal excretion of metaiodobenzylguanidine after therapeutic doses in cancer patients and its relation to dose and creatinine clearance. Nucl Med Commun 1995;16(09):767-772

22 Basu S. Dose fractionation in 131I-metaiodobenzylguanidine (MIBG) therapy: should the tumour biology and intent of therapy be the guide? Eur J Nucl Med Mol Imaging 2010;37(09): 1798-1799 